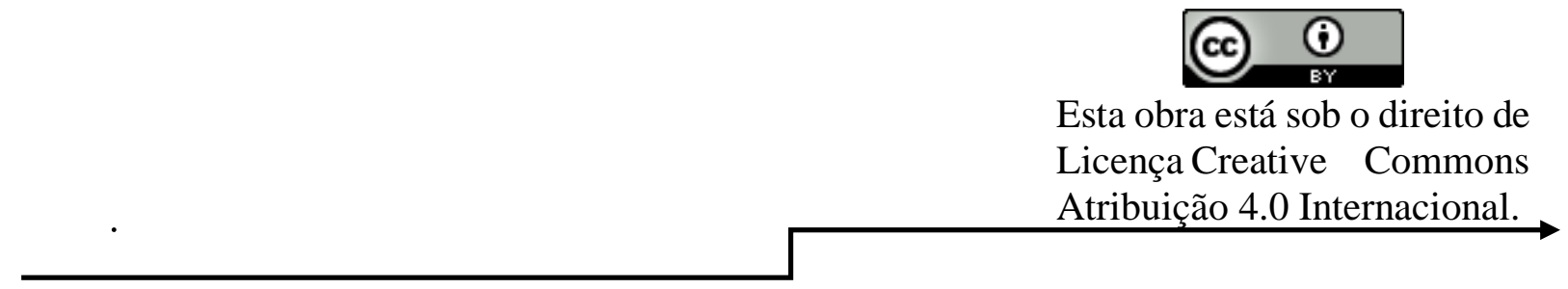

\title{
OS IMPACTOS DAS POLÍTICAS PÚBLICAS DE EDUCAÇÃO
}

\author{
Ivaldo Sales Nascimento Júnior ${ }^{l}$ \\ Eduardo Cabral da Silva ${ }^{2}$
}

\section{RESUMO}

As políticas públicas educacionais são às tomadas de decisões do governo direcionadas ao ambiente escolar, as instituições educacionais que promovem o ensino-aprendizagem, que impactam diretamente no sistema educacional brasileiro. Na presente pesquisa, a análise é sobre os impactos e a influência das políticas públicas educacionais dentro das escolas e na formação de professores. A pesquisa analisou produções científicas publicadas entre 2015 e 2020 , nos sites: BVS e Scielo. O objetivo deste trabalho foi analisar é da importância de políticas públicas educacionais para o sistema educacional brasileiro. Utilizando os descritores estruturados no DeCS e MeSH. O período de coleta dos dados correu no mês de março de 2021. Como critério de inclusão foram utilizados artigos científicos relacionados ao tema e com menos de 5 anos de publicação e, como critérios de exclusão, artigos científicos que não contemplam a temática políticas públicas educacionais. Diante do exposto, conclui-se que as políticas públicas educacionais são necessárias e de extrema importância para o sistema educacional brasileiro, no entanto, carecem de serem efetivadas para que o avanço na educação de fato aconteça.

Palavras-chave: Políticas. Públicas. Educacionais. Sistema. Educacional.

\footnotetext{
1 ivaldosalesjunior@bol.com.br

2 edcs.cabral@gmail.com
} 


\section{INTRODUÇÃO}

A presente pesquisa trata da políticas públicas educacionais e seu impactos nas instituições escolares, por se tratar de tema de extrema relevância no mundo acadêmico tendo despertado muitas pesquisas nesses sentido, assim, busca responder a seguinte pergunta norteadora: quais os impactos das políticas públicas de educação para o sistema educacional brasileiro?

A temática políticas públicas ganhou grandes proporções nos últimos tempos, ocasionando discussões de dimensão ampla, devido ao avanço da redes de comunicação e das condições democráticas por toda parte planeta. Assim, cabe iniciar com um breve resumo do que significa política pública e, a partir daí, política pública educacional (RIBEIRO et. al., 2020).

Deste modo, "política pública é tudo o que um governo faz e deixa de fazer, com todos os impactos de suas ações e de suas omissões" (AZEVEDO, 2003, p. 38). Política pública está relacionada diretamente com a tomada de decisões do governo, ou seja, o povo não tem a responsabilidade direta nas tomadas de decisões, pois, é representado dentro de um governo, sendo o governo o agente capaz de implementar as políticas públicas (RIBEIRO et. al., 2020).
Em se tratando de políticas públicas educacionais, apenas o conceito acima sofre uma restrição, sendo delimitado a área da educação. Políticas públicas educacionais são as ações e omissões do governo relacionadas ou direcionadas a educação. No entanto, o termo educação é um termo muito abrangente, devendo, também ser restringido quando se tratar de políticas públicas educacionais. Assim, políticas públicas educacionais têm como objetivo específico a educação escolar e, de modo geral, são aplicadas às questões escolares RIBEIRO et. al., 2020).

As políticas públicas educacionais correspondem às tomadas de decisões do governo direcionadas ao ambiente escolar, as instituições educacionais que promovem o ensino-aprendizagem, podendo citar como exemplo de decisão, a construção do prédio, a formação docente, a matriz curricular etc. Toda a escola é atingida pelos impactos, direta ou indireta, decorrentes das políticas públicas educacionais (RIBEIRO et. al., 2020).

Os impactos da políticas públicas educacionais no sistema educacional são inúmeros já que como visto acima tem uma grande abrangência dentro do ambiente escolar, o que envolve a prática docente e a formação dos professores. Assim, as políticas públicas educacionais, num país democrático como o Brasil, deve ser tratada diferenciada de região para região, de 
estado para estado e, até, de município para município, atendo uma forma federativa de educação para atender um direito do cidadão legalmente protegido (PINTO et. al., 2020).

Nesse contexto, a políticas educacionais têm um papel essencial na disposição do currículo dos cursos de

\section{MÉTODOLOGIA}

A metodologia aplicada ao presente artigo é a revisão sistemática, que apresentou as etapas dispostas no Quadro 1 abaixo. Respeitando a identificação dos artigos pré-selecionados e selecionados através da leitura dos agentes indexadores licenciatura, sendo a formação de professores pensada de acordo com o atual momento político que norteia a educação (PINTO et. al., 2020).

Deste modo, a presente pesquisa tem como objetivo geral analisar a importância de políticas públicas educacionais para o sistema educacional brasileiro.

das publicações, como resumos, palavraschave e títulos; formação de uma biblioteca individual, bem como, a avaliação crítica dos estudos selecionados; análise, interpretação e discussão dos resultados e a exposição da revisão no formato de artigo, que apresenta sugestões para estudos futuros.

Quadro 1 - Etapas da Revisão Sistemática.

\begin{tabular}{|c|c|c|c|c|}
\hline ETAPA & $\begin{array}{l}\text { TÓPICOS DE } \\
\text { CADA } \\
\text { ETAPA }\end{array}$ & \multicolumn{3}{|c|}{ DETALHAMENTO DE CADA TÓPICO } \\
\hline \multirow[t]{13}{*}{$1^{\mathrm{a}}$} & Tema & \multicolumn{3}{|c|}{$\begin{array}{l}\text { Os Impactos das Políticas Públicas de Educação nas Instituições } \\
\text { Escolares }\end{array}$} \\
\hline & $\begin{array}{l}\text { Pergunta } \\
\text { norteadora }\end{array}$ & \multicolumn{3}{|c|}{$\begin{array}{l}\text { Quais os impactos das políticas públicas de educação para o sistema } \\
\text { educacional brasileiro? }\end{array}$} \\
\hline & Objetivo geral & \multicolumn{3}{|c|}{$\begin{array}{l}\text { Analisar a importância de políticas públicas educacionais para o } \\
\text { sistema educacional brasileiro. }\end{array}$} \\
\hline & $\begin{array}{l}\text { Estratégias de } \\
\text { busca }\end{array}$ & \multicolumn{3}{|c|}{$\begin{array}{l}\text { Cruzamento de descritores por meio do operador booleano AND; } \\
\text { Uso de descritores estruturados (codificação) no DECS ou } \\
\text { MESH; } \\
\text { Uso de metadados (filtros). }\end{array}$} \\
\hline & \multirow{3}{*}{$\begin{array}{l}\text { Bancos de } \\
\text { terminologias }\end{array}$} & Banco & \multicolumn{2}{|c|}{ Link } \\
\hline & & DeSC & \multicolumn{2}{|c|}{ http://decs.bvs.br/ } \\
\hline & & $\mathrm{MeSH}$ & \multicolumn{2}{|c|}{ https://www.ncbi.nlm.nih.gov/mesh } \\
\hline & \multirow{3}{*}{$\begin{array}{l}\text { Descritores } \\
\quad \text { livres e } \\
\text { estruturados }\end{array}$} & Descritor & DeSC (Registro) & MeSH (Identificador Único) \\
\hline & & $\begin{array}{l}\text { Políticas } \\
\text { Públicas }\end{array}$ & 12075 & D011640 \\
\hline & & Educação & 4562 & D004493 \\
\hline & $\begin{array}{l}\text { String de } \\
\text { busca }\end{array}$ & \multicolumn{3}{|c|}{$\begin{array}{l}\text { Planejamento END Gestão AND Educação } \\
\text { "Avaliação da educação" } \\
\text { "Planejamento educacional" }\end{array}$} \\
\hline & & \multicolumn{3}{|c|}{$\begin{array}{ll}\text { Link } \\
\end{array}$} \\
\hline & & \multicolumn{2}{|c|}{ BVS } & https://bvsalud.org/ \\
\hline
\end{tabular}




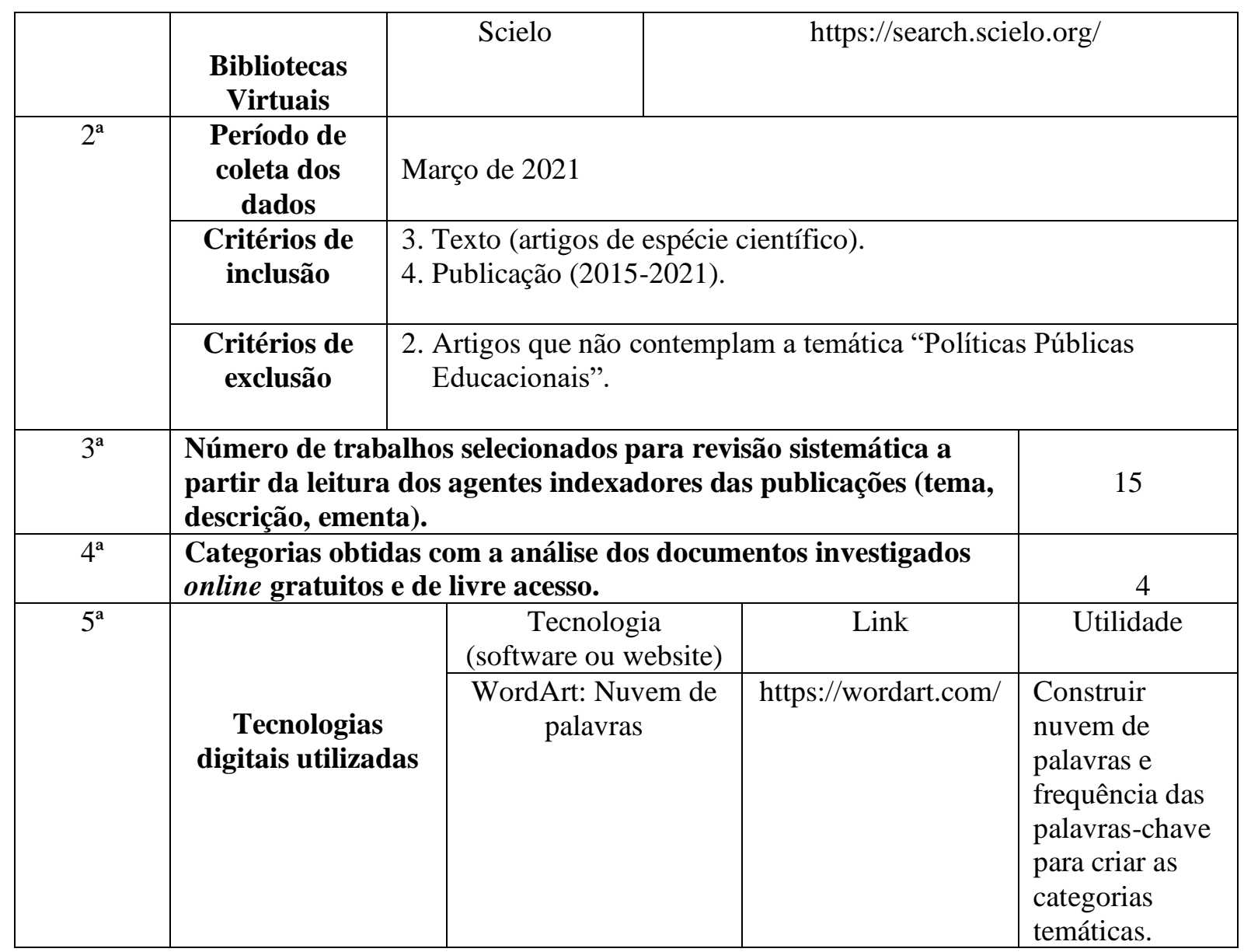

Fonte: Elaborada pelos autores.

\section{RESULTADOS}

Quadro 2 - Total de documentos disponíveis nas Plataforma BVS e Scielo, obtidos por string de busca.

\begin{tabular}{|c|c|c|c|c|}
\hline $\begin{array}{c}\text { String de } \\
\text { busca }\end{array}$ & $\begin{array}{c}\text { Bases de } \\
\text { dados } \\
\text { Plataforma }\end{array}$ & $\begin{array}{c}\text { Total de } \\
\text { publicaçõ } \\
\text { es sem o } \\
\text { filtro }\end{array}$ & $\begin{array}{c}\text { Publicaçõ } \\
\text { es } \\
\text { disponíve } \\
\text { is após } \\
\text { aplicar os } \\
\text { filtros }\end{array}$ & $\begin{array}{c}\text { Publicações } \\
\text { aproveitada } \\
\text { s na } \\
\text { Revisão } \\
\text { Sistemática }\end{array}$ \\
\hline $\begin{array}{c}\text { Planejamento } \\
\text { END Gestão } \\
\text { AND Educação }\end{array}$ & BVS & 168.135 & 199 & 3 \\
$\begin{array}{c}\text { Políticas } \\
\text { Fúblicas AND } \\
\text { Formação de } \\
\text { Professores }\end{array}$ & Scielo & 1474 & 263 & 16 \\
"Avaliação da \\
educação" \\
\cline { 2 - 5 }
\end{tabular}


Fonte: Elaborada pelos autores.

Conforme o quadro acima demonstra, a quantidade de artigos encontrados foi 169.609 publicações científicas nas plataformas pesquisadas, destas, após a utilização de filtros, restaram
462 artigos, do quais foram realizados 20 downloads, que atenderam todos os critérios de inclusão, assim, sendo submetidos às etapas da revisão sistemática.

Quadro 3 - Descrição dos artigos conforme os critérios de inclusão.

\begin{tabular}{|c|c|c|c|c|}
\hline ARTIGO & AUTOR(A) & TEMA & $\begin{array}{c}\text { ANO DA } \\
\text { PUBLICAÇÃ } \\
\text { O }\end{array}$ & CONCLUSÃO \\
\hline 1 & $\begin{array}{l}\text { Adir } \\
\text { Valdemar } \\
\text { Garcia; } \\
\text { Jaime } \\
\text { Hillesheim }\end{array}$ & $\begin{array}{l}\text { Pobreza } \\
\text { desigualdades } \\
\text { educacionais: uma } \\
\text { análise com base nos } \\
\text { Planos Nacionais de } \\
\text { Educação e nos } \\
\text { Planos Plurianuais } \\
\text { Federais }\end{array}$ & 2017 & $\begin{array}{l}\text { A pesquisa } \\
\text { desenvolvimento evidencia } \\
\text { que, nos períodos aludidos, os } \\
\text { PNEs e os PPAs } \\
\text { caracterizaram-se por } \\
\text { formalmente apresentar } \\
\text { propostas de ampliação das } \\
\text { políticas sociais voltadas para } \\
\text { o combate à pobreza e à } \\
\text { diminuição das desigualdades } \\
\text { sociais e educacionais, a } \\
\text { partir de diversos programas } \\
\text { sociais, especialmente do } \\
\text { Programa Bolsa Família. Os } \\
\text { temas, conceitos e ações } \\
\text { encontrados nos instrumentos } \\
\text { de gestão analisados são } \\
\text { problematizados à luz de } \\
\text { referenciais da teoria social } \\
\text { crítica. }\end{array}$ \\
\hline 2 & $\begin{array}{ll}\text { Donaldo } \\
\text { Bello de } \\
\text { Souza; } \\
\text { Janaína } \\
\text { Specht da } \\
\text { Silva } \\
\text { Menezes }\end{array}$ & $\begin{array}{l}\text { Planos estaduais de } \\
\text { educação: desafios às } \\
\text { vinculações com } \\
\text { outros instrumentos } \\
\text { de gestão local da } \\
\text { educação }\end{array}$ & 2017 & 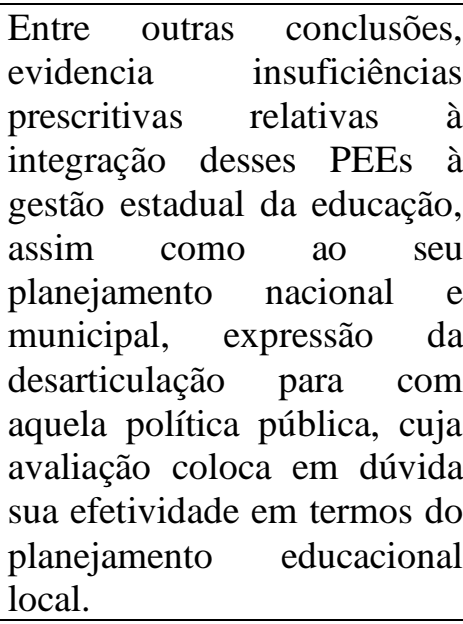 \\
\hline 3 & $\begin{array}{l}\text { Eliza } \\
\text { Bartolozzi } \\
\text { Ferreira }\end{array}$ & $\begin{array}{lr}\text { Gestão dos } & \text { sistemas } \\
\text { municipais } & \text { de } \\
\text { educação: } & \\
\text { planejamento } & \text { e }\end{array}$ & 2015 & $\begin{array}{l}\text { Ademais, é fundamental que } \\
\text { seja cumprido o papel nuclear } \\
\text { do Estado, no sentido de } \\
\text { colaborar para a superação }\end{array}$ \\
\hline
\end{tabular}




\begin{tabular}{|c|c|c|c|c|}
\hline & & $\begin{array}{l}\text { equilíbrio federativo } \\
\text { em questão }\end{array}$ & & $\begin{array}{l}\text { das dificuldades } \\
\text { orçamentárias, gestionárias e } \\
\text { pedagógicas que afligem os } \\
\text { entes administrativos locais. } \\
\text { Talvez assim o planejamento } \\
\text { educacional possa contribuir } \\
\text { para o desejado equilíbrio } \\
\text { federativo. }\end{array}$ \\
\hline 4 & $\begin{array}{l}\text { Donaldo } \\
\text { Bello de } \\
\text { Souza }\end{array}$ & $\begin{array}{l}\text { As veias abertas do } \\
\text { planejamento } \\
\text { educacional no Brasil }\end{array}$ & 2020 & $\begin{array}{l}\text { Coerentemente ao perfil que } \\
\text { há muito vem perseguindo, } \\
\text { Ensaio também não perde de } \\
\text { vista neste número a } \\
\text { sustentação do valor da } \\
\text { Educação internacional, seja } \\
\text { para a difusão global do } \\
\text { conhecimento relativo aos } \\
\text { países alvos dos artigos } \\
\text { publicados, seja de modo a } \\
\text { contribuir, em particular, para } \\
\text { a reflexão da Educação } \\
\text { brasileira, contribuindo para a } \\
\text { problematização } \\
\text { relativização dos aspectos que } \\
\text { constituem a nossa identidade } \\
\text { e, com isto, concorrendo para } \\
\text { o abandono dos léxicos } \\
\text { dominantes, dos } \\
\text { determinismos e das } \\
\text { preconcepções, de forma a } \\
\text { melhor possibilitar o } \\
\text { conhecimento sobre o nosso } \\
\text { próprio contexto e identidade } \\
\text { sociocultural }\end{array}$ \\
\hline 5 & $\begin{array}{l}\text { Ângelo } \\
\text { Ricardo de } \\
\text { Souza }\end{array}$ & $\begin{array}{l}\text { As condições de } \\
\text { democratização da } \\
\text { gestão da escola } \\
\text { pública brasileira }\end{array}$ & 2019 & $\begin{array}{l}\text { Contudo, em geral, o Brasil } \\
\text { tem crescido nas condições de } \\
\text { democratização da gestão das } \\
\text { escolas, em especial no que } \\
\text { tange ao ambiente escolar } \\
\text { democrático. Por outro lado, } \\
\text { as formas de provimento } \\
\text { democráticas da direção } \\
\text { escolar parecem perder força, } \\
\text { uma vez que a ênfase recai } \\
\text { sobre a utilização de modelos } \\
\text { menos democráticos e que } \\
\text { enfatizam a face técnica ou a } \\
\text { vinculação política e eleitoral } \\
\text { do diretor escolar com o } \\
\text { governo vigente, de forma a } \\
\text { se tratar, ao que parece, de } \\
\text { uma retomada de modelo } \\
\text { patrimonialista da gestão } \\
\text { pública no Brasil. }\end{array}$ \\
\hline 6 & $\begin{array}{l}\text { Emmanuelle } \\
\text { Arnaud }\end{array}$ & $\begin{array}{ll}\text { A } & \text { Coordenação } \\
\text { Federativa do } & \text { MEC }\end{array}$ & 2020 & $\begin{array}{l}\text { Conclui-se que o MEC deve } \\
\text { trabalhar para elevar o nível }\end{array}$ \\
\hline
\end{tabular}




\begin{tabular}{|c|c|c|c|c|}
\hline & $\begin{array}{l}\text { Almeida; } \\
\text { Antonio } \\
\text { Cabral Neto }\end{array}$ & $\begin{array}{l}\text { no Âmbito do PAR: } \\
\text { sinais de arranjos e } \\
\text { regras de decisão para } \\
\text { a gestão educacional }\end{array}$ & & $\begin{array}{l}\text { de conhecimento processual } \\
\text { dos Municípios e resolver as } \\
\text { fragilidades de seus próprios } \\
\text { processos gerenciais. }\end{array}$ \\
\hline 7 & $\begin{array}{l}\text { Marília } \\
\text { Fonseca; } \\
\text { Eliza } \\
\text { Bartolozzi } \\
\text { Ferreira; } \\
\text { Elisangela } \\
\text { Alves da } \\
\text { Silva Scaf }\end{array}$ & $\begin{array}{lr}\text { Planejamento } & \mathrm{e} \\
\text { gestão educacional } \\
\text { no Brasil: hegemonia } \\
\text { governamental } \\
\text { construção } \\
\text { autonomia local da }\end{array}$ & 2020 & $\begin{array}{l}\text { O texto analisa, ainda, o } \\
\text { período 2003-2015, quando } \\
\text { uma nova gestão } \\
\text { governamental instituiu, em } \\
2007 \text {, o Plano de Ações } \\
\text { Articuladas (PAR). O } \\
\text { objetivo principal do plano é } \\
\text { estabelecer uma cultura de } \\
\text { planejamento nas secretarias } \\
\text { municipais de educação e nas } \\
\text { escolas de ensino } \\
\text { fundamental, } \\
\text { instrumento para consolidar a } \\
\text { autonomia local. }\end{array}$ \\
\hline 8 & $\begin{array}{l}\text { Suzana dos } \\
\text { Santos } \\
\text { Gomes; } \\
\text { Savana } \\
\text { Diniz } \\
\text { Gomes de } \\
\text { Melo }\end{array}$ & $\begin{array}{l}\text { Políticas } r \text { de } \\
\text { Avaliação e Gestão } \\
\text { Educacional: } \\
\text { articulações, } \\
\text { interfaces e tensões }\end{array}$ & 2018 & $\begin{array}{l}\text { Os resultados indicam que as } \\
\text { políticas públicas para a área } \\
\text { a partir de } 1990 \text { possuem um } \\
\text { eixo comum: se pautam em } \\
\text { concepções e fins mercantis; } \\
\text { estão imbricadas em todos os } \\
\text { níveis de ensino; e seus } \\
\text { efeitos têm acarretado tensões } \\
\text { e críticas. Estas requerem } \\
\text { aprofundamento de estudos. } \\
\text { Chama-se a atenção para a } \\
\text { ameaça de privatização das } \\
\text { universidades federais, o que } \\
\text { coloca em risco a qualidade } \\
\text { do ensino, a condição dos } \\
\text { professores e a própria } \\
\text { essência e finalidade dessas } \\
\text { universidades, subvertendo a } \\
\text { concepção de gestão } \\
\text { democrática. de }\end{array}$ \\
\hline 9 & $\begin{array}{l}\text { Sandra } \\
\text { Zákia } \\
\text { Sousa; } \\
\text { Cláudia } \\
\text { Oliveira } \\
\text { Pimenta }\end{array}$ & $\begin{array}{l}\text { Avaliação e } \text { Gestão } \\
\text { da Educação Infantil } \\
\text { em Municípios } \\
\text { Brasileiros }\end{array}$ & 2018 & $\begin{array}{l}\text { Em conclusão exploram-se } \\
\text { potencialidades e limites } \\
\text { dessas iniciativas, as quais } \\
\text { trazem pistas para apoiar a } \\
\text { construção de avaliações } \\
\text { potencialmente capazes de } \\
\text { servir a um projeto } \\
\text { educacional que dê } \\
\text { materialidade ao direito à } \\
\text { educação de qualidade às } \\
\text { crianças pequenas. }\end{array}$ \\
\hline 10 & $\begin{array}{l}\text { Bernardo } \\
\text { Mattes } \\
\text { Caprara }\end{array}$ & $\begin{array}{l}\text { Condição de Classe e } \\
\text { Desempenho } \\
\text { Educacional no } \\
\text { Brasil }\end{array}$ & 2020 & $\begin{array}{l}\text { Os resultados empíricos } \\
\text { demonstraram a persistência } \\
\text { dos efeitos da classe social na } \\
\text { conformação dos rendimentos } \\
\text { acadêmicos, ainda que } \\
\text { coexistindo com os impactos }\end{array}$ \\
\hline
\end{tabular}




\begin{tabular}{|c|c|c|c|c|}
\hline & & & & $\begin{array}{l}\text { das variáveis } \\
\text { escolarização, de trajetória } \\
\text { individual e de caráter } \\
\text { pedagógico. }\end{array}$ \\
\hline 11 & $\begin{array}{l}\text { Alex Vieira } \\
\text { da Silva; } \\
\text { Givanildo } \\
\text { da Silva }\end{array}$ & $\begin{array}{l}\text { O planejamento da } \\
\text { educação na } \\
\text { contemporaneidade: } \\
\text { a visão de gestores de } \\
\text { escolas públicas de } \\
\text { Recife e Olinda }\end{array}$ & 2019 & $\begin{array}{l}\text { Ficou perceptível que os } \\
\text { gestores escolares das } \\
\text { instituições pesquisadas não } \\
\text { têm a mesma visão sobre o } \\
\text { planejamento da educação } \\
\text { apresentada nos Planos. }\end{array}$ \\
\hline 12 & $\begin{array}{l}\text { Dirléia } \\
\text { Fanfa } \\
\text { Sarmento; } \\
\text { Jardelino } \\
\text { Menegat; } \\
\text { Vera Lúcia } \\
\text { Ramirez }\end{array}$ & $\begin{array}{l}\text { Educação } \\
\text { qualidade e gestão } \\
\text { pública: a construção } \\
\text { do planejamento de } \\
\text { uma secretaria de } \\
\text { educação }\end{array}$ & 2015 & $\begin{array}{l}\text { Os achados (decorrentes da } \\
\text { análise do conteúdo de } \\
\text { documentos, de observações } \\
\text { no Diário de Campo e } \\
\text { entrevistas) sinalizam para: o } \\
\text { sentimento de pertença, o } \\
\text { empoderamento e o } \\
\text { protagonismo dos sujeitos } \\
\text { envolvidos; a reflexão sobre a } \\
\text { própria práxis; a } \\
\text { (re)construção de conceitos e } \\
\text { a revisão de concepções por } \\
\text { meio da investigação-ação- } \\
\text { formação; relações } \\
\text { interpessoais facilitando o } \\
\text { processo comunicacional e o } \\
\text { fluxo das informações; o } \\
\text { comportamento pró ativo na } \\
\text { busca pela resolução de } \\
\text { problemas; a consolidação de } \\
\text { uma gestão focada em } \\
\text { resultados e a qualificação } \\
\text { dos serviços prestados }\end{array}$ \\
\hline 13 & $\begin{array}{l}\text { Wagner dos } \\
\text { Santos; } \\
\text { Aline de } \\
\text { Oliveira } \\
\text { Vieira; } \\
\text { Bruna } \\
\text { Jéssica } \\
\text { Mathia; } \\
\text { Marciel } \\
\text { Barcelos; } \\
\text { Juliana } \\
\text { Martins } \\
\text { Cassani }\end{array}$ & $\begin{array}{l}\text { Avaliação na } \\
\text { Educação Física } \\
\text { Escolar: analisando } \\
\text { as experiências das } \\
\text { crianças em três anos } \\
\text { de escolarização }\end{array}$ & 2019 & $\begin{array}{l}\text { O processo de análise } \\
\text { evidencia a potencialidade no } \\
\text { uso dos diários como prática } \\
\text { avaliativa longitudinal, pois } \\
\text { as crianças sinalizam a } \\
\text { maneira processual com que } \\
\text { atribuem complexidade aos } \\
\text { seus aprendizados, } \\
\text { expressando as relações } \\
\text { estabelecidas com os saberes } \\
\text { da Educação Física, em três } \\
\text { anos da escolarização. }\end{array}$ \\
\hline 14 & $\begin{array}{l}\text { Rika } \\
\text { Miyahara } \\
\text { Kobayashi; } \\
\text { Gabriela } \\
\text { Denise de } \\
\text { Araújo }\end{array}$ & $\begin{array}{l}\text { Avaliação do } \\
\text { treinamento mediado } \\
\text { por tecnologias } \\
\text { educacionais: revisão } \\
\text { integrativa }\end{array}$ & 2017 & $\begin{array}{l}\text { O treinamento de enfermeiros } \\
\text { e a avaliaçãode impacto em } \\
\text { cenário de campo precisam } \\
\text { ser desenvolvidos no Brasil } \\
\text { sistematicamente. } \\
\text { processo de avaliação deve } \\
\text { envolver o profissional } \\
\text { treinado e ser realizado com } \\
\text { ênfase no suporte para }\end{array}$ \\
\hline
\end{tabular}




\begin{tabular}{|c|c|c|c|c|}
\hline & & & & $\begin{array}{l}\text { transferência e como uma } \\
\text { política de recursos humanos. }\end{array}$ \\
\hline 15 & $\begin{array}{l}\text { Cloves } \\
\text { Antonio de } \\
\text { Amissis } \\
\text { Amorim; } \\
\text { Sirley } \\
\text { Terezinha } \\
\text { Filipak; } \\
\text { Catarina } \\
\text { Moro; } \\
\text { Joaquim } \\
\text { Francisco } \\
\text { Dias Setin }\end{array}$ & $\begin{array}{lrr}\text { Liderança } & \text { e } & \text { gestão } \\
\text { democrática } & \text { na } \\
\text { educação infantil } & \end{array}$ & 2016 & $\begin{array}{l}\text { Conclui-se que tem ocorrido } \\
\text { avanços no campo da gestão } \\
\text { democrática e que a } \\
\text { participação da comunidade } \\
\text { contribui para a transparência } \\
\text { das decisões tomadas, mas } \\
\text { ainda necessita ampliar o } \\
\text { conceito de autonomia, bem } \\
\text { como a participação das } \\
\text { crianças. A superficialidade } \\
\text { do conhecimento teórico } \\
\text { sobre gestão democrática } \\
\text { demanda formação } \\
\text { continuada dos gestores e o } \\
\text { permanente abandono do } \\
\text { improviso no exercício da } \\
\text { função. }\end{array}$ \\
\hline 16 & $\begin{array}{l}\text { Vanda } \\
\text { Mendes } \\
\text { Ribeiro; } \\
\text { Alicia } \\
\text { Bonamino; } \\
\text { Sergio } \\
\text { Martinic. }\end{array}$ & $\begin{array}{l}\text { Implementação de } \\
\text { Políticas } \\
\text { Educacionais e } \\
\text { Equidade: regulação } \\
\text { e mediação }\end{array}$ & 2020 & \begin{tabular}{lrr} 
Conclui-se & que as duas \\
iniciativas são regidas por \\
modelos de regulação \\
similares, & \multicolumn{2}{c}{ instituindo } \\
vigilância & sobre ações e \\
interações dos dirigentes e \\
agentes implementadores, \\
mesclando ryas medidas \\
educativas dos tipos \\
burocrático e pós-burocrático. \\
Esse modelo incorpora \\
instrumentos, técnicas e \\
ferramentas que implicam os \\
atores nos objetivos \\
prescritos, na presença de \\
tensões, \\
capacidade de incidir nas \\
práticas cotidianas.
\end{tabular} \\
\hline 17 & $\begin{array}{l}\text { Pedro } \\
\text { Goergen }\end{array}$ & $\begin{array}{l}\text { Educação } \quad \& \\
\text { Sociedade e as } \\
\text { Políticas Públicas em } \\
\text { Educação }\end{array}$ & 2019 & $\begin{array}{l}\text { Em termos gerais, permanece } \\
\text { a forte impressão de que, ao } \\
\text { longo desses últimos } 40 \text { anos } \\
\text { da história do Brasil, a } \\
\text { política educacional se } \\
\text { moveu, sem centralidade, ao } \\
\text { sabor dos interesses políticos, } \\
\text { econômicos e ideológicos dos } \\
\text { grupos que se sucederam no } \\
\text { poder, sempre em prejuízo } \\
\text { das camadas mais humildes } \\
\text { da população. }\end{array}$ \\
\hline 18 & $\begin{array}{l}\text { Verônica } \\
\text { Belfi } \\
\text { Roncetti } \\
\text { Paulino; } \\
\text { Valdete } \\
\text { Côco } \\
\end{array}$ & $\begin{array}{l}\text { Políticas Públicas } \\
\text { Educacionais: vozes } \\
\text { que emergem no } \\
\text { trabalho docente na } \\
\text { Educação Infantil }\end{array}$ & 2016 & $\begin{array}{l}\text { Os dados sinalizam, no bojo } \\
\text { das políticas públicas } \\
\text { educacionais, que a } \\
\text { constituição da docência na } \\
\text { EI interage com um repertório } \\
\text { hierárquico oficial composto }\end{array}$ \\
\hline
\end{tabular}




\begin{tabular}{|c|c|c|c|c|}
\hline & & & & $\begin{array}{l}\text { de aspectos referentes à } \\
\text { formação requisitada, } \\
\text { atribuições demandadas e } \\
\text { delineamento das carreiras, } \\
\text { com suas políticas de } \\
\text { reconhecimento e } \\
\text { valorização, enfraquecendo a } \\
\text { perspectiva da } \\
\text { indissociabilidade do educar e } \\
\text { cuidar nesse campo. }\end{array}$ \\
\hline 19 & $\begin{array}{l}\text { Rafael } \\
\text { Ângelo } \\
\text { Bunhi Pinto; } \\
\text { Waldemar } \\
\text { Marques; } \\
\text { Leo } \\
\text { Victorino da } \\
\text { Silva. }\end{array}$ & $\begin{array}{l}\text { O Programa Nacional } \\
\text { de Formação de } \\
\text { Professores } \\
\text { PARFOR em uma } \\
\text { Universidade } \\
\text { Comunitária: } \\
\text { impactos e resultados }\end{array}$ & 2020 & $\begin{array}{l}\text { a experiência inovadora da } \\
\text { implementação do Parfor } \\
\text { permite constatar a relação da } \\
\text { Instituição com as } \\
\text { comunidades local e regional, } \\
\text { o compromisso com a } \\
\text { educação e os resultados de } \\
\text { suas práticas e de seus } \\
\text { serviços voltados para essas } \\
\text { comunidades, principalmente } \\
\text { no que se refere à formação de } \\
\text { docentes e outros } \\
\text { profissionais da educação } \\
\text { básica. Aponta também este } \\
\text { artigo os limites e } \\
\text { dificuldades de uma ação } \\
\text { deste tipo destinada à } \\
\text { formação docente. }\end{array}$ \\
\hline 20 & $\begin{array}{l}\text { Hosana } \\
\text { Larissa } \\
\text { Guimarães } \\
\text { Oliveira; } \\
\text { Augusto } \\
\text { César Rios } \\
\text { Leiro. }\end{array}$ & $\begin{array}{l}\text { Políticas } \\
\text { Formação } \\
\text { Professores no Brasil: } \\
\text { referenciais legais em } \\
\text { foco }\end{array}$ & 2019 & $\begin{array}{l}\text { Os resultados sugerem o } \\
\text { protagonismo do poder } \\
\text { executivo federal como } \\
\text { regulador das políticas de } \\
\text { formação de professores da } \\
\text { Educação Básica no País, } \\
\text { indicam esforços para } \\
\text { articular as ações numa } \\
\text { perspectiva sistêmica e } \\
\text { denotam grandes desafios } \\
\text { para tornar realidade o } \\
\text { proposto em lei. }\end{array}$ \\
\hline
\end{tabular}

Fonte: Plataformas: BVS, Scielo, 2021. 
O conteúdo textual foi avaliado através da frequência de palavras, que resultou na nuvem de palavras (Figura 1) elaborada na Plataforma online WordArt. O WordArt é uma ferramenta que agrupa e organiza graficamente as palavras-chave demonstrando as mais frequentes.

Figura 1 - Nuvem de Palavras

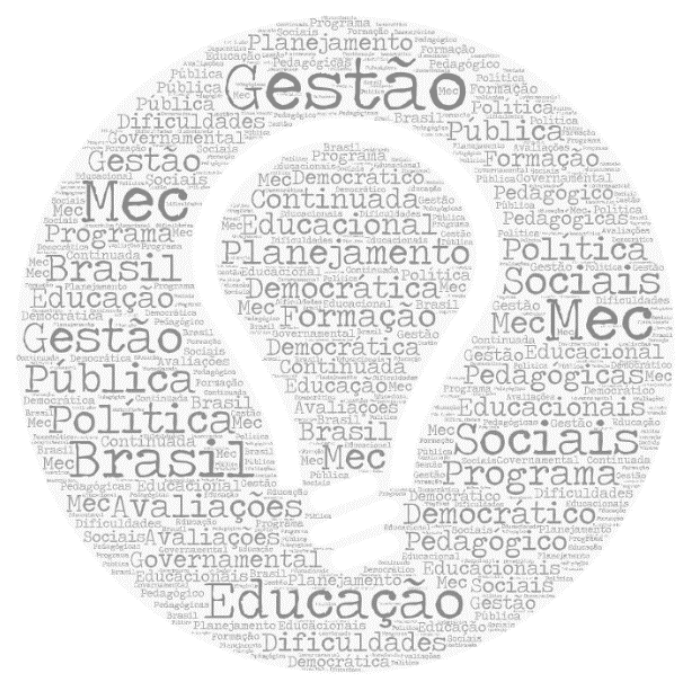

Fonte: Elaborada pelos autores.

Através da Nuvem de Palavras Figura 1, foi possível desenvolver as categorias a partir das palavras em evidência na nuvem de acordo com a análise de conteúdo de Bardin. Assim, foi elaborado a Tabela $1 \mathrm{com}$ a frequência de palavras e as categorias obtidas. Em conformidade com o objetivo da pesquisa, utilizou-se as palavras que apresentaram maior frequência total e que possuem sentido para pesquisa.

Tabela 1 - Frequência das palavras - resultado do WorArt.

\begin{tabular}{|l|c|l|}
\hline \multicolumn{1}{|c|}{ PALAVRAS } & FREQUÊECIA & \multicolumn{1}{c|}{ CATEGORIAS } \\
\hline Gestão & 9 & Impactos das Políticas \\
\hline Educação & 5 & \multirow{3}{*}{ Educacionais no dia a dia Escolar } \\
\hline Planejamento & 5 & \\
\hline Avaliações & 5 & \\
\cline { 1 - 2 } Sociais & 3 & \\
\cline { 1 - 2 } Brasil & 3 & \\
\cline { 1 - 2 } Democrática & 3 & \\
\hline
\end{tabular}




\begin{tabular}{|l|c|l|}
\hline Política & 3 & \\
\hline Programa & 2 & \multirow{2}{*}{ Importância da Política } \\
\hline Educacional & 2 & Educacional na Formação de \\
\hline Pública & 1 & \\
\hline Pedagógicas & 1 & \\
\hline Democrático & 1 & \\
\hline Governamental & 1 & \\
\hline Pedagógico & 1 & \\
\hline Formação & 1 & \\
\hline Continuada & 1 & \\
\hline
\end{tabular}

Fonte: Elaborada pelos autores.

\section{DISCUSSÕES}

\section{Impactos das políticas educacionais no dia a dia escolar}

Como visto acima, as políticas públicas educacionais estão relacionadas com a educação escolar, para o dia a dia escolar; são as determinações do governo direcionadas para educação (RIBEIRO et. al., 2020).

A política pública mais recente $\mathrm{e}$ atual é o Plano Nacional de Educação, esta tem por objetivo o incremento da educação. O Plano Nacional de Educação está previsto na Constituição Federal/1988 e intenciona realizar os deveres do Estado relacionados à Educação (GARCIA; HILLESHEIM, 2017).

Assim sendo, a Constituição Federal traz, em seus artigos 208 e 214, o motivo político dos Planos de Educação. Vejamos:

Art. 208. O dever do Estado com a educação será efetivado mediante a garantia de:

I - educação básica obrigatória e gratuita dos 4 (quatro) aos 17 (dezessete) anos de idade, assegurada inclusive sua oferta gratuita para todos os que a ela não tiveram acesso na idade própria; II - progressiva universalização do ensino médio gratuito;

III - atendimento educacional especializado aos portadores de deficiência, preferencialmente na rede regular de ensino;

IV - educação infantil, em creche e pré-escola, às crianças até 5 (cinco) anos de idade;

$\mathrm{V}$ - acesso aos níveis mais elevados do ensino, da pesquisa e da criação artística, segundo a capacidade de cada um;

VI - oferta de ensino noturno regular, adequado às condições do educando;

VII - atendimento ao educando, em todas as etapas da educação básica, por meio de programas suplementares de material didático-escolar, transporte, alimentação e assistência à saúde.

Art. 214. A lei estabelecerá o plano nacional de educação, de duração decenal, com o objetivo de articular o sistema nacional de educação em regime de colaboração e definir diretrizes, objetivos, metas e estratégias de implementação para assegurar a manutenção e desenvolvimento do ensino em seus diversos níveis, etapas e modalidades por meio de ações integradas dos poderes públicos das diferentes esferas federativas que conduzam a: I - erradicação do analfabetismo; 
II - universalização do atendimento escolar;

III - melhoria da qualidade do ensino;

IV - formação para o trabalho; $\mathrm{V}$ - promoção humanística, científica e tecnológica do País. VI - estabelecimento de meta de aplicação de recursos públicos em educação como proporção do produto interno bruto.

Observe que os planos de educação representam as políticas públicas educacionais, e são documentos que possuem força de lei, com base constitucional, esses documentos apresentam metas que objetivam a garantia do direito à educação de qualidade e o avanço desse direito em um determinado município, estado ou país, pelo lapso de dez anos (SOUZA; MENEZES, 2017).

Os planos educacionais necessitam considerar a realidade nacional, estadual e municipal, deste modo, é extremamente importante a realização de um diagnóstico realizado. As metas, as estratégias e as diretrizes constantes em plano educacional carecem ser definidas tendo como objetivo a melhoria da educação dentro da realidade apresentada (FERREIRA, 2015).

As políticas públicas educacionais causam alterações no dia a dia da escola, no cotidiano escolar, pois provocam alterações dentro da escola, ou seja, nos seus princípios e na sua maneira de se organizar e desenvolver o trabalho escolar, impactando diretamente nas práticas pedagógicas dos docentes (FONSECA; FERREIRA; SCAF, 2020).

Assim, é evidente que todas as metas do Plano Nacional de Educação, respeitando a sua condição de política pública que é, está direcionada para a melhoria da educação, e assim, refletindo diretamente no cotidiano escolar, independe de serem escolas públicas, municipais, estaduais ou particulares. As políticas públicas educacionais, como leis que são, somente por este fato não mudarão a realidade de nenhuma escola, a não ser que esta comunidade escolar seja propícia a tais alterações (FERREIRA, 2015).

Como o Plano Nacional de Educação apresenta metas, essas podem ser divididas em blocos de representação, em uma análise de maneira geral. Assim, um primeiro bloco de metas seriam as metas estruturantes. As metas estruturantes (Metas 1, 2, 3, 5, 6, 7, 9, 10 e 11), que objetivam a garantia do direito à educação básica com qualidade, se referem à universalização da alfabetização, ao acesso e à ampliação da escolaridade e das oportunidades educacionais (ALMEIDA; CABRAL NETO, 2020).

Já, o segundo bloco de metas (Metas 4 e 8), se propõe estritamente à redução das desigualdades e à valorização da diversidade, percurso indispensáveis para a igualdade. Assim deve ser a política pública, ou seja, deve buscar meios para 
reduzir as desigualdades e proporcionar igualdade de oportunidades, através do fortalecimento dos sistemas educacionais com características inclusivas em todas as suas etapas, oportunizar acesso pleno à educação básica gratuita e obrigatória (GOMES; MELO, 2018).

Como terceiro bloco (Metas 15 a 18), temos a valorização dos profissionais da educação. Essas metas são consideradas estratégicas, pois, o sucesso das metas anteriormente citadas depende sucesso delas. Todos concordam que um efetivo de profissionais da educação, em uma escola, que estejam motivados e que sejam comprometidos com os alunos, é fator determinante para o sucesso de qualquer política educacional que procure efetivar a qualidade citada na Constituição Federal/1988 (SOUZA, 2019).

O quarto bloco (Metas 12, 13 e 14), está direcionado ao ensino superior, que, normalmente, é encargo dos governos federal e estaduais, o que não desobriga os municípios, apenas esse nível educacional, em sua maioria, fazem parte dos sistemas federal e estaduais. Observe que professores e demais profissionais da educação que atuarão nos municípios serão formados no ensino superior, colaborando para a geração de renda, bem como, para o desenvolvimento socioeconômico da região (ALMEIDA; CABRAL NETO, 2020).

Diante do exposto, as metas propostas no Plano Nacional de Educação buscam ter suas raízes plantadas nas instituições públicas de ensino, vez que, não tem como se fazer educação sem as escolas e sem os professores (SOUZA, 2019).

Diante disto, e como já dito em linhas anteriores, o simples fato do plano ser uma lei e possuir grandes metas, não mudará realidade social. A lei para ter efetividade e eficácia dentro da sociedade é necessário que seja apropriada por todos e, para isso, deve condizer com a realidade da comunidade escolar.

Importância da política educacional na formação de professores.

\begin{tabular}{|c|l|}
\hline \multicolumn{2}{|c|}{ ENSINO SUPERIOR NO BRASIL } \\
\hline ANO & \multicolumn{1}{c|}{ ACONTECIMENTO HISTÓRICO } \\
\hline 1912 & $\begin{array}{l}\text { Movimentos sociais. } \\
\text { Primeira universidade no Estado do Paraná (duração de três } \\
\text { anos - Universidade só era reconhecida em cidades com mais } \\
\text { de 100.000 habitantes). }\end{array}$ \\
\hline 1920 & $\begin{array}{l}\text { Universidade Federal do Rio de Janeiro - UFRJ (cursos } \\
\text { superiores de Medicina, Direito e a Escola Politécnica). }\end{array}$ \\
\hline 1930 & $\begin{array}{l}\text { Crise de 1929 (rompimento da oligarquia) e movimentos } \\
\text { sociais da década de 1930. }\end{array}$ \\
\hline 1932 & $\begin{array}{l}\text { Universidade de São Paulo - USP, (cursos de Filosofia, } \\
\text { Ciências e Letras). }\end{array}$ \\
\hline
\end{tabular}


Como visto acima, a luta pela formação superior veio agregado a movimentos sociais e foi ganhando espaço no decorrer das décadas, bem como mudando o objetivo que impulsionava a buscar o ensino superior. Assim, somente a partir de 1970, o curso superior passou a ser buscado pela exigência de se ter uma formação, em busca de melhorias na qualidade de vida e a própria busca do conhecimento (CAPRARA, 2020).

Ocorre que a instituições não acompanharam o capitalismo e, assim, com a grande demanda e um desajustamento na infraestrutura, incluindo aí, uma péssima fiscalização, ocasionou uma super defasagem na qualidade e no rendimento do ensino superior, que perdura até os dias atuais (SILVA; SILVA, 2019).

Diante de tantas mudanças ocorridas no ensino superior e relacionadas aos movimentos sociais, na década de 1960, as Universidades Federais iniciaram um movimento de deslocamento dos grandes centros urbanos para as áreas suburbanas, buscando com isso afastar os alunos militantes das grandes manifestações. Movimento contrário fez as faculdades particulares (SARMENTO et. al., 2015).
No entanto, os critérios para ingresso em uma Universidade Federal permaneceram os mesmos, ou seja, ainda faziam seleção, de modo, que a classe média, com melhor preparo, ingressava nos melhores cursos, enquanto que os cursos menos favorecidos ficavam para a classe de baixo nível. Com isso, o ensino privado ganhou espaço tendo grande ascensão (SANTOS, 2019).

Observe que o ensino superior público tem seu olhar voltado para a pesquisa. Já o ensino superior privado seu olhar está direcionado para o mercado de trabalho. Desta forma, muitas instituições privadas tentam gerar nos seus alunos o incentivo necessário para a pesquisa, o questionamento, mas muitas vezes a estrutura da instituição não é qualificada o suficiente, não se adaptando a esse método de ensino. Essas instituições, normalmente, têm como público trabalhadores e pessoas com maior idade, que não conseguiram passar no vestibular ou que não tiveram oportunidade de estudar anteriormente (KOBAYASHI; ARAÚJO, 2017).

Essa análise do ensino superior se faz necessário para compreensão do processo de formação de professores e a importância das políticas públicas educacionais para tanto. A formação do 
professor é pensada com base nas políticas públicas educacionais em busca do atendimento das exigências da educação básica (AMORIM, 2016).

Assim, o aluno deve ser formado para ser um investigador, pesquisador, dentro e fora das universidades, e este conhecimento científico deve acompanhalo por toda sua vida. $\mathrm{O}$ professor pesquisador e reconhecido como tal, proporciona resultados inovadores para a instituição a qual leciona e para o dia a dia em sala de aula com seus alunos. No entanto, para que o professor pesquisador desenvolva seu trabalho com excelência é necessária uma estrutura que atenda às suas necessidades, o que muitas vezes não acontece, devido a várias limitações causadas pelas condições físicas do ambiente de trabalho (RIBEIRO, 2020).

Além de ser um pesquisado, o professor em formação necessita obter conhecimentos que atenda as exigências da educação básica, mas o que ocorre é que instituições possuem um plano de ensino totalmente defasado, formando professores inseguros que, em sua maioria, não se

\section{CONCLUSÕES}

As políticas públicas educacionais são políticas voltadas para aumentar a qualidade de ensino dentro das instituições escolares, ou seja, são elaboras para atingir sentem aptos a estar a frente de uma sala de aula, a dar aulas, ficando evidente a deficiência didática dos cursos de licenciatura, de modo geral (GOERGEN, 2019).

Compreende-se que a conjuntura político educacional interfere diretamente nas instituições escolares, incluindo as de curso superior, e desta maneira são direcionados para a teoria, o conhecimento essencial para a formação do professor, ficando a qualidade em segundo plano (PAULINO; CÔCO, 2016).

Assim, deve-se compreender o momento histórico em que as políticas públicas educacionais são elaboradas para, também, compreender como o sistema educacional irá efetiva-las dentro de suas realidades, buscando atender as necessidades dos alunos, através de uma formação adequada dos profissionais da educação, que não visem apenas teoria e conteúdos superficiais que não capacitam o profissional a atender a demanda que o aguardam dentro da sala de aula (OLIVEIRA; LEIRO, 2019).

o ambiente escolar e causar mudanças que elevem o ensino-aprendizagem.

Os impactos que estas políticas causam são diretos e envolvem toda a comunidade escolar, gestores, professores, alunos, pais, demais profissionais e, inclusive o próprio Estado. 
O plano nacional de educação, como política pública atual, busca através de metas favorecer o ensino-aprendizagem se adequando a realidade de cada instituição escolar, inclusive interferindo diretamente na formação do professor e valorização da categoria.

No entanto, é possível observar que falta muito para que o plano nacional de educação, incluindo os planos Estaduais e Municipais, de fato se tornem realidade, sendo necessário inclusive que a

\section{REFERÊNCIAS}

ALMEIDA, E. A.; CABRAL, N., A. Coordenação Federativa Do Mec No Âmbito Do Par: Sinais De Arranjos E Regras De Decisão Para a Gestão Educacional. Educação em Revista, v. 36, p. 1-16, 2020.

AZEVEDO, Sérgio de. Políticas públicas: discutindo modelos e alguns problemas de implementação. In: SANTOS JÚNIOR, Orlando A. Dos (et. al.). Políticas públicas e gestão local: programa interdisciplinar de capacitação de conselheiros municipais. Rio de Janeiro: FASE, 2003.

AMORIM, C. A. A. et al. Liderança e gestão democrática na educação infantil. Psicologia Argumento, v. 34, n. 87, p. 333-349, 2017.

CAPRARA, B. M. Condição de Classe e Desempenho Educacional no Brasil.

Educação \& Realidade, v. 45, n. 4, p. 128, 2020.

SOUSA, S. Z.; FERREIRA, E. B. Gestão dos sistemas municipais de educação: Planejamento e equilíbrio federativo em comunidade abrace o plano e se proponha a efetiva-lo. Ou seja, carecem de deixar de representar apenas uma carta com boas intenções para de fato serem realizados dentro das escolas. Além do mais, a execução destes planos necessita, também, da questão orçamentária, da disponibilidade do gestor em se comprometer em garantir verbas suficientes para a execução de tais planos.

questão. Ensaio, v. 23, n. 88, p. 545-566, 2015.

FONSECA, M.; FERREIRA, E. B.; SCAFF, E. A. DA S. Planejamento e gestão educacional no Brasil: hegemonia governamental e construção da autonomia local. Educar em Revista, v. 36, p. 1-18, 2020.

GARCIA, A. V.; HILLESHEIM, J. Pobreza e desigualdades educacionais: uma análise com base nos Planos Nacionais de Educação e nos Planos Plurianuais Federais. Educar em Revista, n. spe.2, p. 131-147, 2017.

GOERGEN, P. Educação \& Sociedade e as Políticas Públicas em Educação. Educ. Soc., Campinas, v.40, e0215966, 2019.

KOBAYASHI, R. M. Avaliação do treinamento mediado por tecnologias educacionais: revisão integrativa. J.

Health Inform, v. 11, n. 3, p. 85-91, 2019.

SOUZA, Â. R. As condições de democratização da gestão da escola pública brasileira. Ensaio: aval. pol. públ. Educ., 
Rio de Janeiro, v.27, n.103, p. 271-290, abr./jun. 2019.

PIMENTA, C. O. Avaliação e Gestão da Educação Infantil em Municípios Brasileiros. Educação \& Realidade, v. 43, n. 4, p. 1277-1300, 2018.

PINTO, R. Â. B.; MARQUES, W.; SILVA, L. V. DA. O Programa Nacional de Formação de Professores - PARFOR em uma Universidade Comunitária: impactos e resultados. Avaliação, Campinas; Sorocaba, SP, v. 25, n. 03, p. 769-790, nov. 2020.

RIBEIRO, V. M.; BONAMINO, A.; MARTINI, S. Implementação de Políticas Educacionais e Equidade: regulação e mediação. Cad. Pesqui., São Paulo, v. 50, n. 177, p. 698-717, jul./set. 2020.

SANTOS, W. DOS et al. Avaliação Na Educação Física Escolar: Analisando As Experiências Das Crianças Em Três Anos De Escolarização. Movimento (ESEFID/UFRGS), v. 25, p. e25047, 2019.
SARMENTO, D. F.; MENEGAT, J.;

RAMIREZ, V. L. Educação de qualidade e gestão pública: a construção do planejamento de uma secretaria de educação. Revista Brasileira de Política e Administração da Educação - Periódico científico editado pela ANPAE, v. 31, n. 2, p. 313, 2016.

SOUZA, D. B. DE. As veias abertas do planejamento educacional no Brasil.

Ensaio: Avaliação e Políticas Públicas em Educação, v. 28, n. 109, p. 833-842, 2020 .

SOUZA, D. B. DE; MENEZES, J. S. D. S. Planos estaduais de educação: desafios às vinculações com outros instrumentos de gestão local da educação. Revista

Brasileira de Educação, v. 22, n. 71, p. 123, 2017.

SILVA, A. V. SILVA, G. O planejamento da educação na contemporaneidade: a visão de gestores de escolas públicas de Recife e Olinda. Rev. bras. Estud. pedagog., Brasília, v. 100, n. 256, p. 675696, set./dez. 2019. 